\title{
Malária cerebral no Ceará: relato de caso
}

\author{
Cerebral Malaria in Ceará: a case report
}

\author{
Marcus Davis Machado Braga ${ }^{1}$, Geritza Chagas Alcântara ${ }^{2}$, \\ Cristiane Nobre da Silva ${ }^{3}$ e Cyntia Gioconda Honorato Nascimento 4
}

\section{RESUMO}

A partir de um caso de malária cerebral no Ceará observa-se a possibilidade dessa ocorrência em zona não endêmica, secundária a retardo diagnóstico. Além da gravidade da doença, incomum para a espécie determinada, Plasmodium vivax, verifica-se a possível existência de infecção mista e sua potencial disseminação na presença do vetor.

Palavras-chaves: Malária cerebral. Malária atípica. Malária importada. Malária no Ceará. Brasil.

\section{ABSTRACT}

Starting from a case of cerebral malaria in Ceará, the authors get the attention for that possibility of this occurrence in no-endemic zone, due to the retard of the diagnosis. Besides the serious implications of the disease, uncommon for this determined species, Plasmodium vivax, it is observed the probable existence of mixed infection and the potential dissemination with the presence of the sand fly transmitter.

Key-words: Cerebral malaria. Atypical malaria. Imported malaria. Malaria in Ceará. Brazil.

Malária é uma doença tipicamente tropical que necessita de todos os fatores envolvidos no seu ciclo para se manter endêmica. Geralmente, isto acontece próximo às florestas, onde reside o vetor, em zonas com a presença de pessoas infectadas, que permitem a persistência do parasito em seu reservatório humano ${ }^{7}$. No Brasil, a malária é endêmica em áreas como a Amazônia onde se encontram presentes várias espécies de vetores. Em alguns estados nordestinos litorâneos, como o Ceará, é encontrado um vetor adaptado à maior salinidade do litoral, o Anopheles aquasilis. 0 menor acesso do mosquito a hospedeiros, contudo, mantém a região longe da endemia.

Com os maiores deslocamentos migratórios ou mesmo turísticos ocorridos nos últimos anos, notifica-se constantemente casos de doenças importadas a partir de zonas endêmicas vizinhas. Tais casos geralmente são identificados e tratados pelos órgãos competentes, impedindo a disseminação e a ocorrência de formas mais graves. Os profissionais de saúde destas regiões, entretanto, dificilmente têm contato com estes casos e desconhecem o potencial explosivo da patologia, seja em termos de acometimento individual ou coletivo. Desta forma, é grande a possibilidade de ser esquecido, no atendimento médico diário, o diagnóstico diferencial com malária sendo, assim, conveniente um alerta para o fato, por isso a importância desse caso.

\section{RELATO DE CASO}

0 paciente SFB, de 25 anos, militar, natural de Pinheiros, no Maranhão, procedente de Boa Vista, Roraima. Sem antecedentes de malária, chegou à Fortaleza com queixa de febre e colúria e história de tratamento antimicrobiano prescrito para infecção urinária, no início de fevereiro de 1997, por médico da região de procedência. Reavaliado no Ceará, em 4 de março, foi feito 0 diagnóstico presuntivo de hepatite, tendo em vista a severa adinamia, anorexia, colúria, diarréia pouco expressiva e dores musculares. Foi instituída medicação sintomática e colhido material para avaliação laboratorial. Antes dos resultados dos exames solicitados, a febre se elevou substancialmente, com calafrios, prostração, sonolência e desorientação. No dia 11 de março, foi examinado no

\footnotetext{
1. Departamento de Patologia e Medicina Legal da Faculdade de Medicina da Universidade Federal do Ceará, Fortaleza, CE. 2. Hospital Geral de Fortaleza, Fortaleza, CE. 3. Hospital Albert Sabin, Fortaleza, CE. 4. Acadêmica de Medicina na Universidade Federal do Ceará, Fortaleza, CE.

Endereço para correspondência: Prof. Marcus Davis M. Braga. Departamento de Patologia e Medicina Legal/FM/UFC.Rua Alexandre Baraúna s/n, Porangabuçu, 60430-160 Fortaleza, CE.

Tel: 5585288.8301

e-mail: bragamarcus@hotmail.com.br

Recebido para publicação em 12/11/2002

Aceito em 13/11/2003
} 
Corpo de Bombeiros, apresentando-se acentuadamente pálido, com hepatomegalia, espaço de Traube ocupado e doloroso, além de sintomatologia secundária a acometimento do SNC, como desorientação, delírios, torpor e prostração. Apresentava diarréia, pressão arterial de $110 \times 70 \mathrm{mmHg}$, taquicardia e febre de $39,8^{\circ} \mathrm{C}$. Foi encaminhado ao hospital de doenças infecciosas de Fortaleza com suspeita de malária, confirmada pelo esfregaço de sangue periférico, sem referência à espécie de Plasmodium. Nesse momento apresentava hipopotassemia com $\left[\mathrm{K}^{+}\right]=3,2 \mathrm{mg} / \mathrm{dl}$, [uréia $]=57 \mathrm{mg} / \mathrm{dl}$ e $[$ creatinina $]=1,5 \mathrm{mg} / \mathrm{dl}$. Admitido em UTI, na mesma noite recebeu quinina endovenosa e oxigênio. Apresentou melhora expressiva no dia seguinte, apesar do recrudescimento da diarréia e náuseas. Houve regressão quase integral do quadro clínico em quatro dias, quando lhe foi dada alta hospitalar. Após esta, persistiram anorexia e dores musculares, sendo-lhe prescrito vimbramicina durante cinco dias. Um mês depois, após esforço físico importante, os sintomas voltaram, sem desorientação ou prostração. Realizado esfregaço de sangue periférico, diagnosticouse Plasmodium vivax. Foi instituído, então, tratamento com cloroquina e primaquina por 14 dias. Logo o paciente se tornou assintomático, permanecendo sem queixas por três meses, quando, outra vez após exercício extenuante, os sintomas periféricos ressurgiram. Apresentava, nesse momento, pressão arterial de 110x75mmHg, pulso de 76ppm, sem outras alterações evidentes ao exame clínico. A pesquisa de sangue periférico voltou a revelar $P$. vivax e novamente lhe foram prescritos primaquina e cloroquina. Nos primeiros dias após o início do tratamento, regressou a seu estado natal, onde lhe foi prescrito mefloquina. Desde então permanece assintomático.

\section{DISCUSSÃO}

Segundo dados da Organização Mundial de Saúde a zona endêmica da malária atinge cerca de 2,2 bilhões de pessoas no mundo, abrangendo 90 países ${ }^{11} 13$, mantendo-se endêmica na presença do vetor, o mosquito Anopheles. No Brasil atinge todo 0 Norte, estendendo-se ao Maranhão ocidental, sendo exportados, ocasionalmente, alguns casos para outras regiões, sendo 99\% deles na Amazônia Legal 5 . No Ceará, foram notificados em média 87 casos anuais entre os anos de 1997 a 2001, com um último caso autóctone em 1996, até o reaparecimento, em surto importante, em 2002 (Tabela 1)

Dentre suas formas graves, a malária pode acometer o cérebro com frequiência entre $0,01 \%$ e $16 \%$ dos casos ${ }^{9}$. A disfunção cerebral pode apresentar-se com qualquer grau de redução da consciência,

Tabela 1 - Casos registrados de malária no Ceará, segundo a sua autoctonia e o ano, de 1997 a 2002.

\begin{tabular}{lrrrrrr}
\hline Casos & 1997 & 1998 & 1999 & 2000 & 2001 & $2002^{* *}$ \\
\hline Importados & 78 & 68 & 90 & 135 & 64 & 34 \\
Autóctones* & 0 & 0 & 0 & 0 & 0 & 509
\end{tabular}

*Casos que surgem localmente a partir de casos importados.

**Até 08/08/2002

Fontes: Ceará. Secretaria de Saúde. Informe Malária. 25. set. 2002. Fundação Nacional de Saúde. delírio, embotamento mental ou anormalidades neurológicas, apresentando um bom prognóstico desde que o tratamento não seja retardado $0^{5}$. Assim, o paciente não evolui para o coma profundo, exigido por Warrell et al ${ }^{10}$ na rigorosa classificação convencionada de malária cerebral. Tosta et $\mathrm{al}^{9}$, entretanto, já definem 0 acometimento cerebral como alterações ao nível de consciência, confusão mental, desorientação, prostração e fraqueza extrema, que podem evoluir para o coma. Charbase et $\mathrm{al}^{1}$ referem a existência de formas graves pelo Plasmodium vivax (febre terçã benigna) apenas nos casos em que não foi possível excluir com certeza a infecção mista. Sachdev ${ }^{6}$, entretanto, já sugere a etiologia por infeção pelo P. vivax. Islam ${ }^{4}$, no Paquistão, descreveu um caso de complicação cerebral devido ao Plasmodium vivax, assim como Tilluckdharry ${ }^{8}$, associou a infecção a um quadro de psicose.

No presente caso, infelizmente, por ocasião do diagnóstico de malária cerebral, apenas foi evidenciado o gênero do parasito. Somente com a recidiva é que a espécie, $P$. vivax, foi identificada. Provavelmente a recidiva da doença deu-se a partir de formas exoeritrocíticas, hipnozoítas, freqüentes nesta espécie de parasito ${ }^{3}$, no qual a resistência ao tratamento não é comum 5 . 0 acometimento cerebral, no entanto, é tipicamente relacionado ao P. falciparum, por sua maior capacidade de proliferação, agregação hemática e de liberação local de TNF - fator de necrose tumoral ${ }^{2}$. Neste estudo, se a forma grave foi provocada por infecção mista ou exclusivamente. pelo P. vivax, não foi possível precisar. A persistência da infecção não adequadamente tratada, possibilitaria o desenvolvimento de uma alta densidade parasitária de $P$. vivax, levando a produção de citocinas, a níveis mais elevados, que poderiam se relacionar com a alteração cerebral ${ }^{2}$. Contudo, a importância deste caso reside na dificuldade da doença ser diagnosticada em áreas não endêmicas, por conta de sua raridade, permitindo o avançar clínico até formas graves e incomuns, como o acometimento cerebral, seja qual for 0 tipo de espécie infectante. Vale ressaltar, ainda, que a existência do mosquito Anopheles aquasalis no estado do Ceará ${ }^{7}$, transforma-0 numa zona potencial para a disseminação da endemia, se os casos importados não forem contidos rapidamente, tal como está acontecendo no presente ano.

\section{REFERÊNCIAS BIBLIOGRÁFICAS}

1. Charbase D, Drouet F, Bidault P, Subra JF, Achard J. Forme neurologique ou accès permicieux à Plasmodium malariae. Discussion physiopathologique à propos d'une observation. Bulletin de la Societe de Pathologie Exotique 74:171-175, 1981.

2. Cruz MFF, Ribeiro CTD. Imunologia e imunopatologia da malária. In: Veronesi R, Focaccia R (eds) Tratado de Infectologia, Atheneu, São Paulo, p.1268-1272, 1999.

3. Gogswell FB, Krotoski WA, Hollingdale MR, Gwadz RW. Identification of hypnozoites and tissue schizonts of Plasmodium vivax and P. cynomolgi by the imunoperoxidase method. American Journal of Tropical Medicine and Hygiene 32:1454-1456, 1983.

4. Islam N, Gamruddin K. Unusual complications in benign tertian malaria. Tropical and Geographical Medicine 47:141-143, 1995.

5. Ministério da Saúde. Manual de terapêutica da malária. Brasília, p.15, 2001.

6. Sacgdev HP. Can Plasmodium vivax cause cerebral malaria? Indian Pediatrics 33:791-792, 1996 
7. Tauil PL. Epidemiologia da malária. In: Veronesi R, Focaccia R (eds) Tratado de Infectologia. Atheneu, São Paulo, p. 1264-1268, 1999

8. Tilluckdharry CC, Chadee DD, Doon R, Nehall J. A case of vivax malaria presenting with psychosis. West Indian Medical Journal 45:39-40, 1996.

9. Tosta CE, Lopes ER, Chapadeiro E. Patologia das principais doenças tropicais no Brasil - Malária. In: Lopes ER, Chapadeiro E, Tafuri WL (eds) Bogliolo L Patologia. 6a edição, Guanabara Koogan, Rio de Janeiro, p. 1250-1263, 2000.

10. Warrell DA, Loareesuwan S, Warrell MJ, Kesemsarn P, Intaraprasert R, Bunnag D, Harinasuta T. Dexamethasone proves deleterious in cerebral malaria. A double- blind trial in 100 comatose patients. The New England Journal of Medicine 306:313-319, 1982.

11. World malaria situation in 1992. Part I. Weekly Epidemiological Record 69:309-344, 1994

12. World malaria situation in 1992. Part II. Asia West of Indian. Weekly Epidemiological Record 69:317-321, 1994.

13. World malaria situation in 1992. Part III. Weekly Epidemiological Record 69:325-330, 1994 